\title{
Malaria in Papua New Guinea Implications for the British Army
}

\author{
Major A Henderson, \\ MRCP, RAMC, Consultant Physician \\ *British Military Hospital, Hong Kong, BFPO 1
}

SUMMARY: Malaria poses the greatest health threat to British soldiers engaged in jungle training in Papua New Guinea. This paper provides detailed epidemiological information gained following a visit to the Papua New Guinea Malaria Research Unit in January 1986.

\section{Introduction and Background}

Papua New Guinea extends from the equator to Cape Baganowa at latitude $11.4^{\circ}$ south, and from the border with Irian Jaya at $141^{\circ}$ east longitude to $160^{\circ}$ east longitude. The territory comprises a central land mass with many small islands. The population in 1980 was a little over 3 million.

The climate is tropical. In the lowland coastal areas the temperature ranges between a maximum of $32^{\circ} \mathrm{C}$ and a minimum of $21^{\circ} \mathrm{C}$. The annual rainfall varies from 1000 $\mathrm{mm}$ near Port Moresby, to more than $6000 \mathrm{~mm}$ in the Huon peninsula. In the lowland jungles, the annual rainfall is about $4000 \mathrm{~mm}$. There is no dry season, but relatively less rain falls between May and October.

The British Army holds company strength exercises in the jungles of the Sepik district near Wewak (Map I), and in the hinterland of Port Moresby. In the last 3 years, 42 cases of malaria have occurred in Gurkha soldiers involved in these exercises. As Papua New Guinea is likely to be the venue for future exercises, it has become imperative to review the malaria situation so that rational decisions can be made regarding protective measures.

\section{Malaria Epidemiology}

Malaria is endemic in all areas below 5000 feet, with only occasional Plasmodium vivax transmission at higher altitudes. In the coastal jungles the high temperatures and humidity favour malaria transmission throughout the year ${ }^{1}$. In the Sepik and Madang districts mosquito biting rates are enormous. An unprotected man might expect more than 100 bites in one night ${ }^{3}$. As the prevalence of mosquitoes harbouring malarial parasites may approach $4 \%$, the malaria risk to soldiers is therefore also enormous ${ }^{4}$. The area around Port Moresby is less malarious because of the drying effect of the South East Trade winds ${ }^{1}$.

The opinions expressed and conclusions reached in this article are those of the author and do not necessarily reflect Defence Medical Services Directorate Policy.

${ }^{*}$ British Military Hospital Rinteln BFPO 29

\section{Plasmodial Species}

All four human plasmodia are found in Papua New Guinea. Until 10 years ago, $P$. vivax and $P$. falciparum were dominant and equally represented ${ }^{3,5}$. Considerable changes have occurred since then however, and the current distribution is, $P$. falciparum $70 \%-80 \%, P$. vivax $15 \%-20 \%, P$. malariae $5 \%$ and $P$. ovale $1 \%{ }^{2}$. Mosquitoes harbouring both $P$. falciparum and $P$. vivax are common, and in the Sepik district, mixed human parasitaemia accounts for just under half of alp infections ${ }^{5}$. Recent British Army experience confirm? the high prevalence of mixed $P$. falciparum and $P$. viva $\Phi$ infections ${ }^{6.7}$.

Map I. Malaria Distribution in Papua New Guinea

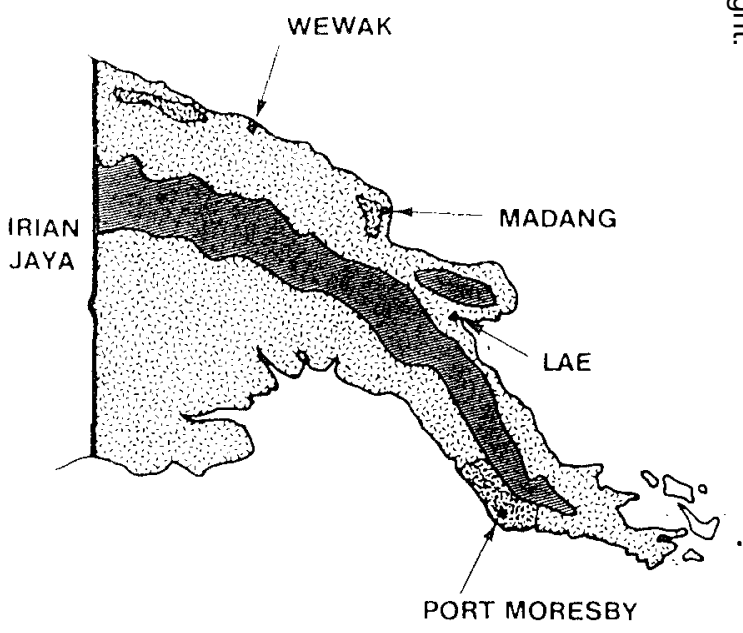

PORT MORESBY
HYPERENDEMIC

MESOENDEMIC

HYPOENDEMIC OR AMALARIOUS 


\section{Malarial Vectors}

Of the 20 potential vector mosquitoes found in Papua New Guinea, only three are important. They are $A$. punctulatus, $A$. farauti and $A$. koliensis. These mosquitoes are long-lived and strongly anthropophilic $^{3,4}$. A. punctulatus favours river valleys but feeds indoors, with a peak biting period around midnight ${ }^{3,4}$. $A$. farauti favours the coastal areas. It bites indoors with a peak biting period before midnight ${ }^{3,4,8,9}$. A. koliensis is common around Wewak and feeds indiscriminately throughout the night ${ }^{4}$.

The vector control programme has failed and has now been abandoned ${ }^{2}$.

\section{Plasmodial Resistance to Anti-malarial Drugs}

Chloroquine. $P$. vivax, $P$. ovale and $P$. malariae remain fully sensitive. In 1976 cholorquine resistant $P$. falciparum was confirmed in Papua New Guinea ${ }^{10}$ and has since been widely reported. Currently, about $70 \%$ of $P$. falciparum is chloroquine resistant, but mostly at the RI level (RI $85 \%$, RII 6\% RIII 9\%) ${ }^{11,12}$.

Amodiaquine. Non-falciparum plasmodia remain sensitive, but amodiaquine resistant $P$. falciparum was reported from the Madang district in $1981^{13}$. Although amodiaquine may be superior to chloroquine in areas of chloroquine resistance, ${ }^{14}$ the drug has recently proved too toxic for large scale prophylaxis ${ }^{15}$.

Proguanil. This drug was introduced during World War II and initially proved very effective ${ }^{16,17}$. Resistance however soon appeared, and in $1960 P$. falciparum was reported to be breaking through a dose of $200 \mathrm{mg}$ daily, mirroring the situation in Vietnam ${ }^{17-26}$. The strains of $P$. vivax and $P$. malariae found in Papua New Guinea seem also to have reduced sensitivity to proguanil ${ }^{20,22}$. There has been renewed interest in proguanil-chloroquine combinations for prophylaxis of chloroquine resistant malaria $^{27}$. Recent British Army experience has shown this to be relatively ineffective in Papua New Guinea ${ }^{7}$.

Pyrimethamine. Little information is available from Papua New Guinea although a report from 1961 suggested resistance was present ${ }^{19}$.

Fansidar. There have been no formal prophylaxis studies, but in a test of therapeutic efficacy, a failure rate of $10 \%$ was noted against $P$. falciparum ${ }^{28}$. Fansidar is intrinsically weak against $P$. vivax ${ }^{29,30}$.

Maloprim. Like fansidar, maloprim is weak against $P$. vivax $^{30,31}$. It is however, extremely effective against chloroquine sensitive and chloroquine resistant $P$. falciparum in Papua New Guinea ${ }^{31}$.

Primaquine. The Chesson strain of $P$. vivax found in Papua New Guinea is tolerant to primaquine, requiring higher than usual dosage for radical cure ${ }^{32}$.

\section{Prophylactic Options for the British Army}

\section{Reducing man mosquito contact}

Strict anti-mosquito discipline can greatly reduce malaria casualties ${ }^{33}$. Insect repellents incorporating diethyltoluamide should be applied every 3-4 hours, long sleeves and trousers should be worn between dusk and dawn and mosquito nets used within the limits of the tactical situation. An interesting new development is net impregnation with Permethrin, which is effective against tsetse fly and probably against malaria vectors ${ }^{34-36}$ Trials with this agent in the military context are urgently required.

\section{Chemoprophylaxis}

Proguanil and proguanil-chloroquine seem ineffective $^{6,7}$. Fansidar is too toxic and may be inadequate in Papua New Guinea ${ }^{28.37}$. Maloprim has proven efficacy against $P$. falciparum in Papua New Guinea ${ }^{31}$ but should be combined with chloroquine to give protection against non-falciparum malaria. A chloroquine-maloprim combination is recommended by the Australian Government for visitors to Papua New Guinea ${ }^{38}$ and by a local expert $^{11}$. Maloprim has toxic potential. Given twice weekly it causes agranulocytosis with a frequency of about $1: 2000^{39}$. Given once weekly, agranulocytosis appears to be rare, although at the expense of a slight degradation of efficacy ${ }^{40,41}$. Proguanil plus dapsone ișo another possibility. This proved successful in Vietnam ${ }^{26}$ but there remains a definite risk of agranulocytosis ${ }^{26,42}$ and in Papua New Guinea protection against $P$. vivax i uncertain. Unlike maloprim, the regimen is not of proven worth in Papua New Guinea ${ }^{30}$.

On return from Papua New Guinea, a course o primaquine should be given to all men with normat levels of red cell G6PD to destroy $P$. vivax hypozoites ${ }^{25}$.

\section{Conclusions}

The jungles of Papua New Guinea are intensely malarious. Prophylaxis is complicated by multiple resistance to anti-malarial drugs. The best prophylaxis appears to be rigorously enforced anti-mosquito discipline combined with chloroquine base $300 \mathrm{mg}$ weekly plus maloprim one tablet weekly, starting one week before an exercise and continuing for 6 weeks after its end. On return, primaquine $7.5 \mathrm{mg}$ thrice daily should be given to all men with normal levels of G6PD, for 14 days. As proguanil is used routinely for long-term prophylaxis in Hong Kong, this could be continued for administrative convenience, at little cost in side-effects.

\section{REFERENCES}

1. DiJK VAN W J O M and Parkinson A D. Epidemiology of malaria in New Guinea. Papua New Guinea Med J 1974, 17: $17-21$

2. MoIR $\mathbf{J}$ and Gardener P. Malaria control through the Health Services in Papua New Guinea. Papua New Guinea MedJ. (Press).

3. SPEnCER T, SPEnCER M and Venters D. Malaria vectors in Papua New Guinea. Papua New Guinea MedJ 1974; 17 : 22-30.

4. Peters W. Studies on the epidemiology of malaria in New Guinea. Part II. Holoendemic Malaria. The ento- 
mological picture. Trans R Soc Trop Med Hyg 1960; 54: 249-254.

5. Peters W. Studies in the epidemiology of malaria in New Guinea. Part I. Holoendemic Malaria. The clinical picture. Trans R Soc Trop Med Hyg 1960; 54: 242-249.

6. Henderson A et al. Polyresistant malaria in Gurkba soldiers returning from Papua New Guinea. $J$ R Army Med Corps 1986; 132: 37-41.

7. Henderson A, Simon J and Melia W. Failure of malaria chemoprophylaxis with a proguanil-chloroquine combination in Papua New Guinea. Trans $R$ Soc Trop Med Hyg (Press)

8. SPencer M. Blood preferences of Anopheles farauti. Papua New Guinea Med J 1964: 7: 19-22.

9. AfIFIS E D et al. Biting preference and malaria transmission pattern in the Anopheles punctulatus complex (Diptera: Culicidae) on Papua New Guinea. Aust J Exp Biol Med Sci 1980; 58: 1-17.

10. GRIMMOND T R and RILEY I D. Chloroquine resistant malaria in Papua New Guinea. Papua New Guinea Med J 1976; 19: 184-185.

11. Biddulph J. Malaria Prophylaxis. Which Drug. Papua New Guinea Med J 1983; 26: 127-130.

12. DULAY I S et al. A study of Plasmodium falciparum chloroquine resistance and its geographical distribution in Papua New Guinca. Papua New Guinea Med J. (Press).

13. STACE J. A trial of malaria prophylaxis in children 0-5 years of age by weekly administration of amodiaquine 1977-1981. Final report to WHO. Madang. Papua New Guinea.

14. SPENCER H C et al. Amodiaquine more effective than chloroquine against Plasmodium falciparum malaria on the Kenya coast. Lancet 1984; 1: 856-957

15. Hatton C S A et al. Frequency of severe neutropenia associated with amodiaquine prophylaxis against malaria. Lancet 1986; 1: 411-414

16. Gunther C E M. Proguanil hydrochloride (paludrine) in the prevention and treatment of malaria in New Guinea. Trans R Soc Trop Med Hyg 1951; 44: 473-478.

17. Gunther C E M, Fraser N M and Wright W G. Proguanil and malaria among non-tolerant New Guinea natives. Trans R Soc Trop Med Hyg 1952; 46: 185-190.

18. Gunther C EM and Wright W G. Further observations on Proguanil in New Guinea. Trans $R$ Soc Trop Med Hyg $1953 ; 47 ; 156-158$.

19. MEU WISSEN J H E Th. Resistance of Plasmodium falciparum to pyrimethamine and proguanil in Netherlands New Guinea. Am J Trop Med Hyg 1961; 10: 135.

20. WHO. Resistance of malaria parasites to drugs. Report of a WHO Scientific Group. WHO Technical Report Series 296. WHO Geneva 1965.

21. RIECKMIANN K H. A new repository antimalarial agent Cl-564 used in a field trial in New Guinea. Trans $R$ Soc Trop Med Hyg 1967; 61: 189-198.

22. PETERS W. In: Chemotherapy and Drug Resistance in Malaria. Academic Press. London \& New York. 1970.

23. Colbourne M and Sstevenson K A P. Anti-malarial programme in Papua New Guinea. WHO Report 1970.
24. Thompson P E and WERKEL L M. In; Antimalarial agents. Chemistry and Pharmacology. Academic Press. London \& New York. 1972.

25. WHO Chemotherapy of malaria and resistance to antimalarials. Report of a WHO Scientific Group. Technical Report Series 529. WHO Geneva 1973.

26. BLACK R H. Malaria in the Australian Army in South Vietnam. Successful use of proguanil-dapsone combination for chemoprophylaxis of chloroquine resistant falciparum malaria. Med J Aust 1973: 1: 1265-1270.

27. Colbourne M J and Draper L C. Proguanil for malaria prophylaxis, Lancet 1983; 1: 1228.

28. DARLOW B et al. Sulfadoxine-Pyrimethamine for the treatment of acute malaria in children in Papua New Guinea. Am J Trop Med Hyg 1982; 31: 1-9.

29. DOBERSTYN E B et al. Treatment of vivax malaria with sulfadoxine-pyrimethamine and pyrimethamine alone Trans R Soc Trop Med Hyg 1979; 73: 15-17.

30. Public Health Laboratory Malaria Reffrince LABORATORY. Malaria prophylaxis for long-term visitors. BMT 1983; 283: $214-218$.

31. VRBova H et al. Trial of amodiaquine $(10 \mathrm{mg} / \mathrm{kg})$ and maloprim as chemotherapcutic agents in the Madang district. Seventeenth Symposium of the Medical Society of Papua New Guinea. Rabaul 1981.

32. Peters W. Antimalarial drug resistance: an increasing problem. Br Med Bull 1982; 38: 187-192.

33. WiNter P E et al. Malaria discipline as prophylaxis, Mil Med 1967; 132: 917-919.

34. Laveissiere C, CoUret D and KIENON JP. Lutte contr les glossines riveraines a l'aide de pieges biconiques impregnes d'insecticide, en zone de savare humide I Resultats quantitatifs obtenus lors des premiers essai Cah Orstom Ser Ent Med et Parasitol 1980; 43:209-221.

35. LAVFissiere C, Courft D and KienON J P. Lutte contre्? les glossines riveraines a laide de pieges biconiques impregnes d'insecticide en zone de savara humide III. Resultat quantitatifs obtenus lors des premier essais Cah Orstom Ser Ent Med et Parasitol 1980; 43; 223-228.

36. DARRIET Fet al. Evaluation of the efficacy of Permethrinimpregnated and perforated mosquito nets against the vectors of malaria. WHO/VEC/84, 899: WHL/MCL/84 1008 .

37. Whо. Malaria Chemoprophylaxis, WHO Weekly Epidemiological Record 1985;24: 181-183.

38. Commonwealth Department of Health. Guidelines on malaria prophylaxis for areas with chloroquine resistant malaria. Canberra Australia April 301980.

39. FrIman G et al. Agranulocytosis associated with malaria prophylaxis with Maloprim. $\mathrm{Br}$ Med $J$ 1983; 286: 1244-1245.

40. Hutchinson D B A and Farquhor J A. Chemopro phlaxis of Malaria in Africa. BrMed J 1983; 286: 62 .

41. COOK I F and MCGREGOR J W. Inadequate prophylaxis of Plasmodium falciparum malaria with once wcekly Maloprim therapy. Med J Aust 1982; 2: 563-564.

42. Ognibent A J. Agranuloxytosis due to Dapsone Ann Intern Med 1970; 72: 521-524. 